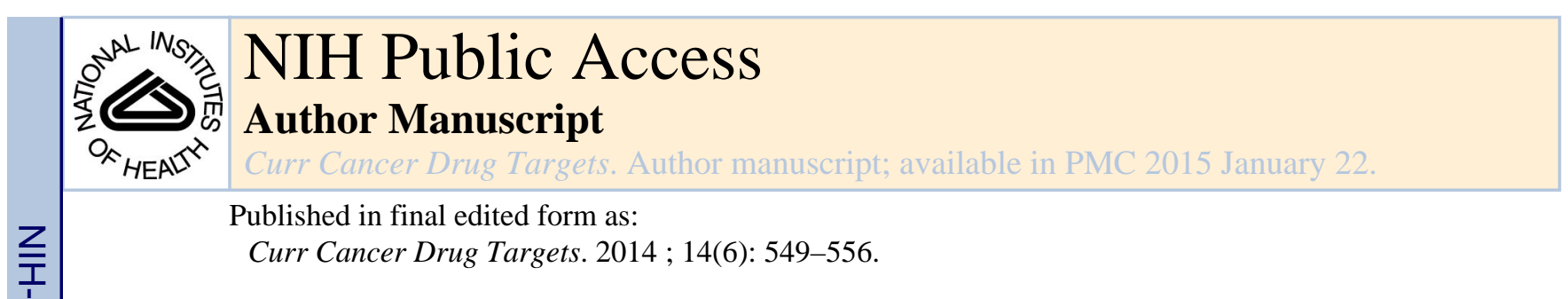

\title{
NEDD4: A Promising Target for Cancer Therapy
}

Xiantao Ye ${ }^{1, \#}$, Lixia Wang ${ }^{1, \#}$, Bingxue Shang $^{1}$, Zhiwei Wang ${ }^{1,{ }^{*}}$, and Wenyi Wei ${ }^{2,{ }^{*}}$

${ }^{1}$ The Cyrus Tang Hematology Center and Collaborative Innovation Center of Hematology, Jiangsu Institute of Hematology, the First Affiliated Hospital, Soochow University, Suzhou 215123, China

2Department of Pathology, Beth Israel Deaconess Medical Center, Harvard Medical School, MA 02215, USA

\section{Abstract}

The Neuronally expressed developmentally downregulated 4 (NEDD4), functioning largely as an E3 ubiquitin ligase, has been demonstrated to play a critical role in the development and progression of human cancers. In this review, to understand the regulatory mechanism(s) of NEDD4 as well as the signaling pathways controlled by NEDD4, we briefly describe the NEDD4 upstream regulators and its downstream ubiquitin substrates. Moreover, we further discuss its oncogenic roles in human malignancies. Therefore, targeting NEDD4 could be a potential therapeutic strategy for treatment of human cancers.

\section{Keywords}

Cancer; E3 ligase; NEDD4; oncogene; target; therapy; ubiquitination

\section{INTRODUCTION}

Ubiquitination is a post-translational modification that controls protein degradation by the ubiquitin proteasome system (UPS). Ubiquitination is generally catalyzed by three enzymes: the E1 ubiquitin-activating enzyme, the E2 ubiquitin-conjugating enzyme, and the E3 ubiquitin-protein ligase [1]. The E1 enzyme utilizes ATP to activate ubiquitin, a 76 amino acid protein, and subsequently transfers ubiquitin to the E2 enzyme. Then, E2 binds with E3 ligase and subsequently E3 ligase transfers the ubiquitin to specific substrates for degradation by the $26 \mathrm{~S}$ proteasome in an ATP-dependent manner [2] (Fig. 1). It is important to note that there is monoubiquitination or polyubiquitination due to the consecutive addition of ubiquitin moieties to target proteins. Clearly, E3 ligase is critical for governing substrate specificity [3].

(C) 2014 Bentham Science Publishers

*Address correspondence to these authors at the Department of Pathology, Beth Israel Deaconess Medical Center, Harvard Medical School, 330 Brookline Ave., Boston, MA 02215; Tel: (617) 734-2495; Fax: (617) 735-2480; wwei2@ bidmc.harvard.edu. Cyrus Tang Hematology Center, Soochow University, Room 703-3601, 199 Ren Ai Road, Suzhou Industrial Park, Suzhou, Jiangsu 215123,

China; Tel: +86 (512) 65880899; Fax: +86 (512) 65880929; zhiwei@ gmail.com.

\# Ye X and Wang L contributed equally to this work.

CONFLICT OF INTEREST

The authors declare that they have no conflict of interest. 
In general, based on common structural motifs, E3 ubiquitin ligases are categorized into two major classes, including the RING (Really interesting new gene)-type E3s and HECT (Homologous to E6-AP C-terminus)-type E3s [4-6]. It has been established that RING-type E3s catalyze the transfer of the ubiquitin protein from E2 enzyme to a substrate, whereas HECT-type E3s form a transient, covalent linkage with ubiquitin and then transfer the ubiquitin to its substrate [7]. Among RING-type E3 ligases, the SCF (Skp1-Cullin 1-F-box) complex and the APC (Anaphase promoting complex) have been well characterized. The SCF complex is composed of SKP1 (S-phase kinase-associated protein 1), Rbx1/Roc1, Cullin 1, and variable F-box proteins [1]. Each of the 69 putative F-box proteins in human genome consists of two major functional domains: the C-terminal domains that bind to specific substrates, and the F-box motif that interacts with the SCF complex via binding to SKP1 [8]. It has been demonstrated that APC and SCF are the major driving forces to regulate cellular processes [1]. Specifically, the SCF complex largely regulates cellular entry into $\mathrm{S}$ phase by degradation of various cell cycle regulators including G1 CKIs (Cdk kinase inhibitors) and G1 cyclins [1], whereas APC governs timely cell cycle progression in both M and G1 phases [8].

HECT-type E3s have attracted high attention in recent years since E6AP (E6-associated protein, also known as UBE3A) was first described as a HECT type of E3s. It has been well documented that there are about 30 HECT-type E3s including NEDD4 (Neuronally expressed developmentally downregulated 4) family, HERC family and other HECT members [9]. The HECT domain is located at the C-terminus of E3s. The NEDD4 family has nine members in mammals including NEDD4 (also known as NEDD4-1), NEDD4L (also known as NEDD4-2), SMURF1 (SMAD-specific E3 ubiquitin protein ligases), SMURF2, WWP-1 (WW domain containing E3 ubiquitin protein ligase 1), WWP-2, NEDL1, NEDL2 and ITCH [10]. It has been demonstrated that the NEDD4 structure contains three domains: a C-terminal HECT domain for ubiquitin protein ligation, an Nterminal C2 domain for binding membrane, a central two to four double tryptophan residue (WW) domains for protein-protein interaction through recognizing proline-containing motifs (PY motifs; PPXY) present in its substrates [11] (Fig. 2). Interestingly, recent studies demonstrated that besides the initially discovered role in controlling neuronal function and plasticity in the brain [12], NEDD4 has also been identified to play a pivotal role in the development and progression of human cancers [13]. In the following sections, we will discuss the novel role and regulation of NEDD4 in the pathogenesis of human cancers.

\section{DOWNSTREAM SUBSTRATES OF NEDD4}

As an E3 liagse, NEDD4 exerts its biological function mainly through mediating protein degradation in an ubiquitination-dependent manner in the endoplasmic reticulum, lysosomes and proteasome [14]. The list of identified NEDD4 substrates includes ENaC (Epithelial sodium channel) [15], ADRB2 ( $\beta 2$-adrenergic receptor) [16], AMPA (Amino-3-hydroxy-5methyl-isoxazole-4-propionic acid) receptor [17, 18], Notch [19, 20], pAKT [21], IGF-1R (insulin-like growth factor-1 receptor) [22], VEGF-R2 (vascular endothelial growth factor receptor-2) [23], Cbl-b [24], Deltex [19], EPS15 (Epithelial growth factor receptor substrate 15) [25], Spy1A [26], LATS1 (large tumor suppressor kinase 1) [27], PTEN (Phosphatase and tensin homologue) [28], and MDM2 (Mouse double minute 2 homolog) [29] (Fig. 3). 
Biologically, NEDD4 governs the sodium homeostasis through regulation of the levels of ENaC [15]. In addition, NEDD4-mediated AMPAR ubiquitination regulates receptor turnover and trafficking in the brain [18]. Specifically, NEDD4 overexpression led to AMPAR ubiquitination and reduced AMPAR surface expression and subsequent inhibition of excitatory synaptic transmission, whereas depletion of NEDD4 largely abolished AMPAR degradation [18].

Importantly, various recent studies also revealed a critical role for NEDD4 in tumorigenesis by regulating various downstream signaling pathways. For example, Salah et al. reported that NEDD4 directly interacts with LATS1, leading to ubiquitination and decreased levels of LATS1, and thus inhibited the activity of the Hippo signaling pathway to influence tumorigenensis [27]. It has also been reported that NEDD4 antagonizes the oncogenic Notch signaling by promoting the degradation of Notch and Deltex [19]. Specifically, NEDD4 ubiquitinated and destabilized Notch that PPSY motif in Notch intracellular domain is required for degradation. Knockdown of NEDD4 attenuated Notch activity independently of its ligand binding [19]. Moreover, Notch ligand Deltex is also ubiquitinated and destabilized by NEDD4 in a Notch-dependent manner. These findings suggest that NEDD4 antagonizes Notch signaling pathway through increased degradation of Notch and Deltex [19]. Consistently, another group confirmed that Notch signaling is limited by the E3 ligase activity of NEDD4 [20]. NEDD4 regulates the trafficking of pAKT through promoting ubiquitination of exogenous and endogenous AKT in IGF-1 signaling. IGF-1 signaling stimulates NEDD4-mediated ubiquitination of pAKT, suggesting that regulation of pAKT dynamics by NEDD4 is in a ligand-specific manner [21]. Another study showed that NEDD4 regulates ubiquitination and stability of the IGF-IR. Notably, this process needs Grb10 as an adapter to form a bridge between NEDD4 and the IGF-IR [22]. Moreover, Grb10/NEDD4-mediated multiubiquitination of the IGF-IR regulates receptor internalization [30]. Furthermore, Grb10 induced an increase in the amount of VEGFR2 in part through inhibiting NEDD4-mediated VEGFR2 degradation [23].

Recently, NEDD4 was also identified as an E3 ligase to regulate MDM2 protein stability [29]. NEDD4 promotes MDM2 ubiquitination in a dose- and time-dependent manner, whereas depletion of NEDD4 reduced the half-life of endogenous MDM2 [29]. It has also been reported that NEDD4 polyubiquitinated Beclin 1 and controlled the stability of Beclin 1 [31]. Additionally, Luo et al. reported that NEDD4 is a positive regulator in Hedgehog signaling [32]. They found that overexpression of NEDD4 increased Hedgehog target Gli luciferase reporter activity, whereas loss of NEDD4 diminished Gli-dependent activity [32]. However, the molecular mechanism of NEDD4-regulated Hedgehog pathway remains largely unclear [32]. It is critical to note that NEDD4 also regulates protein trafficking by recycling protein through the endocytic machinery [12]. Taken together, NEDD4 exerts its physiological function mainly through promoting the ubiquitination-dependent degradation of its substrates.

\section{UPSTREAM REGULATORS OF NEDD4}

In recent years, a line of evidence has suggested that NEDD4 could be regulated by multiple factors [14] (Fig. 3). For instance, NEDD4 was found to be phosphorylated by Src [25]. It 
has been demonstrated that NEDD4 is cleaved during apoptosis induced by a variety of stimuli including Fasligation, $\gamma$-radiation, TNF-a, and etoposide [29]. For example, NEDD4 could be cleaved by several caspases during apoptosis, such as caspase-1, caspase-3, caspase-6, and caspase-7 [33]. One study also identified that Grk2 (G protein-coupled receptor kinase) regulated NEDD4 to control epithelial $\mathrm{Na}(+)$ channels [34]. Although PTEN is a substrate of NEDD4, it has been reported that PTEN also downregulated NEDD4 levels in human cancer cells [2]. Moreover, PI3K (phosphoinositide 3-kinase) inhibitor inhibited NEDD4 expression, indicating that NEDD4 regulation is dependent on the phosphatase kinase activity of the PTEN-PI3K pathway [2]. Additionally, FoxM1B (Forkhead box protein M1B) promoted NEDD4 expression, leading to cellular transformation and full malignant phenotype in immortalized human astrocytes [35]. Specifically, overexpression of FoxM1B upregulated NEDD4 and subsequently downregulated PTEN expression, leading to hyper-activation of Akt, which promotes the phosphorylation as well as cytoplasmic retention of FoxO3a in multiple cell lines [30]. Kwak et al. revealed that upregulation of NEDD4 by oxidative stress degrades IGF-1R [36]. This study showed that NEDD4 expression is upregulated in response to hydrogen superoxide through transcriptional activation likely mediated by ROS (reactive oxygen species)-responsive FoxM1B [36]. Moreover, NDRG1 (N-myc downstream regulated gene-1) upregulated NEDD4 expression and subsequently affected the TGF- $\beta$ pathway in pancreatic cancer cells [37].

Our recent study showed that $\beta$-TRCP (beta-transducin repeat-containing protein) governs NEDD4 protein stability by targeting it for ubiquitination and destruction in a casein kinaseI (CKI)-dependent manner [38]. Notably, depletion of $\beta$-TRCP led to increased NEDD4 and subsequently decreased PTEN. Decreased PTEN in turn led to the hyper-activation of Akt to influence tumorigenesis [38]. Additionally, Hong et al. reported that p34, a binding partner of NEDD4, regulates NEDD4 protein stability and controls PTEN degradation [39]. This group found that p34 interacts with the WW1 domain of NEDD4, leading to increased NEDD4 stability and enhanced PTEN degradation [39]. Moreover, an inverse correlation between PTEN and p34/NEDD4 levels was observed in colon cancer tissue samples [39]. Consistently, Jung et al. found that p34SEI-1 positively affected NEDD4 gene expression at both the mRNA and protein levels, leading to downregulation of PTEN and activation of PI3K/AKT signaling pathway [40]. In another study, Lonne et al. reported that PKC $\delta$ (protein kinase $\mathrm{C}$ delta) could regulate the expression of NEDD4 because PKC $\delta$ silencing resulted in increased levels of NEDD4 and subsequent up-regulation of MKP3 (MAP kinase phosphatase 3) in breast cancer cells [41]. Taken together, NEDD4 expression could be controlled by several upstream factors and cell signaling pathways.

\section{ROLE OF NEDD4 IN HUMAN CANCER}

Recently, NEDD4 has been found to play a crucial role in tumorigenesis [13]. Therefore, in the following paragraphs, we will discuss the functions of NEDD4 in cancer cell lines, in animal models, and in human cancer tissue samples. 


\section{NEDD4 Function in Cancer Cell Lines in vitro}

Some studies have demonstrated that NEDD4 is an oncoprotein in promoting cancer cell growth. For example, Eide et al. discovered that depletion of NEDD4 by its small interfering RNA (siRNA) led to reduced growth and altered cell morphology in HCT-15 and LoVo colon cancer cells [42]. Specifically, HCT-15 cells became larger after NEDD4 knockdown, while depletion of NEDD4 in LoVo cells led to the formation of epithelial-like sheets. Moreover, confocal microscopy revealed that depletion of NEDD4 resulted in profound changes in the actin cytoskeleton in HCT-15 and LoVo cell lines [42]. Interestingly, NEDD4 promoted growth of colon cancer cells independently of PTEN and PI3K/AKT signaling [42].

Amodio et al. observed that the overexpression of NEDD4 in non-small-cell lung carcinomas (NSCLC) cell lines facilitated anchorage-dependent and independent growth of lung epithelial cells with loss of RB and p53, whereas depletion of NEDD4 significantly inhibited proliferation of NSCLC cells in vitro and tumor growth in vivo [43]. This oncogenic function of NEDD4 in NSCLC cells could be through inactivation of PTEN. Notably, NEDD4 overexpression promoted the tumorigenicity of NCI-H460 lung cancer cells with intact PTEN gene [43]. Xu et al. found that knockdown of NEDD4 decreased the cell growth in U2OS cells. Interestingly, the extents of growth inhibition induced by depletion of NEDD4 in U2OS cells were significantly larger than that in U2OS cells with p53 knockdown, suggesting that NEDD4 knockdown inhibited cell growth likely in a p53dependent mechanism in U2OS cells [29]. Consistent with these reports, we observed that ectopic expression of a non-degradable NEDD4-AA significantly enhanced cell growth compared to cells expressing WT-NEDD4 [38]. Notably, our results showed that cells expressing NEDD4-AA promoted migration ability. Due to that NEDD4 negatively regulates PTEN, NEDD4 could promote cell growth and migration partly through regulation of the PTEN/AKT signaling pathway in prostate and breast cancer cells [38].

\section{NEDD4 Knockout Mice}

Several studies have revealed that NEDD4 complete null mice are embryonic or perinatal lethal. To this end, Liu et al reported that a null mutation of NEDD4 in mice resulted in perinatal lethality [44]. Some mice died in utero before birth with reduced skeletal muscle fiber sizes and motoneuron numbers [44]. Consistently, it has been shown that homozygous NEDD4 knockout (KO) mice died during late gestation likely due to the loss of NEDD4 from essential non-neuronal organs [45]. In further support of this concept, they found that NEDD4 KO embryos showed a retarded development and half of KO mice had subcutaneous bleedings [45]. Moreover, another study confirmed that disruption of NEDD4 in mice led to an embryonic lethality at mid gestation with vasculature abnormalities and heart defects [46]. The heart defects in NEDD4 KO mice included atrioventricular cushion defects and double-putlet right ventricle [46]. Furthermore, Cao et al. identified that NEDD4-null mice had delayed embryonic development, reduced growth and body weight, and neonatal lethality [47]. In line with these findings, $\mathrm{NEDD}^{-/-}$mouse embryonic fibroblasts (MEFs) have decreased mitogenic activity [48]. Due to the lethality of NEDD4 homozygous KO mice, NEDD4 heterozygous mice were generated for further studies. These heterozygous mice are viable and live to maturity, but have gait abnormalities [49]. As an 
alternative approach to get around the lethality associated with NEDD4 KO mice, the researchers also generated conditional NEDD4 KO mice. Notably, NEDD4 skeletal musclespecific (SMS) KO mice showed heavier denervated muscle weights and larger type II fibre cross sectional areas, suggesting that NEDD4 SMS-KO mice have partial protection from muscle atrophy [50]. Surprisingly, there is no report showing the role of NEDD4 in tumorigenesis using transgenic mouse model, suggesting that additional engineered mouse models are needed to further explore the oncogenic function of NEDD4. For example, it is important to examine whether NEDD4 KO mice are resistant to tumor development induced by loss of PTEN or p53. This goal could be achieved through NEDD4 KO mice crossing with PTEN KO mice or $\mathrm{p} 53 \mathrm{KO}$ mice. These studies will likely provide the rationale for developing NEDD4 targeted therapies as novel anti-cancer treatments.

\section{NEDD4 is Frequently Overexpression in Human Cancers}

In line with the potential oncogenic role of NEDD4, it has been found that NEDD4 is frequently upregulated in a variety of human cancers [13]. For example, NEDD4 has been reported to be overexpressed in prostate and bladder cancer [13]. Similarly, NEDD4 mRNA was significantly increased in all stages of colorectal cancer from premalignant adenoma to stage IV colorectal cancer, whereas both NEDD4L mRNA and proteins were decreased in colorectal cancer samples [51]. Consistently, another group also found overexpression of NEDD4 and downregulation of NEDD4L in colon cancer tissues compared to normal colonic tissues [42]. Jung et al. found that overexpression of NEDD4 was detected in about $60 \%$ breast cancer tissue samples [40]. Moreover, NEDD4 levels were found to be highly associated with p34SEI-1 expression in breast cancer tissues, further suggesting that p34SEI-1 is a positive regulator of NEDD4 [33]. In accordance with these findings, it has also been observed that NEDD4 is overexpressed in $80 \%$ of NSCLC tumor tissues and correlated with the loss of PTEN protein [43]. Surprisingly, it has no association between NEDD4 levels and tumor size, node involvement, grade, or stage. Interestingly, higher expression of NEDD4 was more frequently observed in male patients with NSCLC [43]. It has been shown that NEDD4 is up-regulated in advanced gastric cancer tissues and associated with metastasis compared to adjacent noncancerous gastric tissues [52]. However, Yang et al. reported that NEDD4 expression was increased from normal gastric mucosa to intestinal metaplasia, but decreased from dysplasia to gastric carcinoma, arguing that further investigation is required to explore the role of NEDD4 in gastric carcinomas[53]. Therefore, targeting NEDD4 could be a promising strategy for treatment of human cancers.

\section{CONCLUSION}

In conclusion, NEDD4 plays important oncogenic roles through regulation of its multiple substrates in various human cancers. In this regard, targeting NEDD4 could be a promising therapeutic strategy for treatment of human malignancies. Thus, development of NEDD4 inhibitors is required to inhibit NEDD4 expression, leading to better treatment outcome. One alternative strategy is to target several upstream effectors that govern NEDD4 expression. For example, promotion of the NEDD4 destruction by beta-TRCP could contribute to decreased abundance of the oncoprotein NEDD4. Activation of either $\beta$-TRCP1 or its 
modifying enzyme CKI $\delta$ could reduce NEDD4 levels. Thus, drugs that activate $\beta$-TRCP1 or CKI $\delta$ could be an approach to treat human cancers with high level of NEDD4. It is noteworthy that NEDD4 inhibitors may have unwanted physiological effects such as oncogenic or side effects due to the diversity of targets of NEDD4 including growth factor receptor, ion channels and oncoprotein MDM2. Although NEDD4 as a bona fide anticancer target needs further investigation, the possibility of NEDD4 inhibitors as anti-cancer drugs is intriguing and timely. Therefore, we hope that this article would stimulate further work, specially engineered mouse model, to investigate the molecular mechanism by which NEDD4 mediates tumor development and progression. These further investigations will provide the evidence and the rationale for designing specific NEDD4 inhibitors for treating human cancer patients.

\section{ACKNOWLEDGEMENTS}

This work was supported by grant from NSFC (81172087) and the priority academic program development of Jiangsu higher education institutions. This work was supported in part by the NIH grants to W.W. (GM089763, GM094777 and CA177910). W.W. is an ACS research scholar and a LLS research scholar.

\section{LIST OF ABBREVIATIONS}

$\begin{array}{ll}\text { ADRB2 } & \beta 2 \text {-adrenergic receptor } \\ \text { AMPA } & \text { Amino-3-hydroxy-5-methyl-isoxazole-4-propionic acid } \\ \text { APC } & \text { Anaphase promoting complex } \\ \text { B-TRCP } & \text { beta-transducin repeat-containing protein } \\ \text { CKIs } & \text { Cdk kinase inhibitors } \\ \text { E6AP } & \text { E6-associated protein } \\ \text { ENaC } & \text { Epithelial sodium channel } \\ \text { EPS15 } & \text { Epithelial growth factor receptor substrate 15 } \\ \text { FoxM1B } & \text { Forkhead box protein M1B } \\ \text { Grk2 } & \text { G protein-coupled receptor kinase } \\ \text { HECT } & \text { Homologous to E6-AP C-terminus } \\ \text { IGF-1R } & \text { Insulin-like growth factor-1 receptor } \\ \text { LATS1 } & \text { Large tumor suppressor kinase 1 } \\ \text { MDM2 } & \text { Mouse double minute 2 homolog } \\ \text { MAP } & \text { Mitogen-activated protein } \\ \text { MKP3 } & \text { MAP kinase phosphatase 3 } \\ \text { NDRG1 } & \text { N-myc downstream regulated gene-1 } \\ \text { NEDD4 } & \text { Neuronally expressed developmentally downregulated } 4 \\ \text { PI3K } & \text { Phosphoinositide 3-kinase }\end{array}$




$\begin{array}{ll}\text { PKC } 8 & \text { Protein kinase C delta } \\ \text { PTEN } & \text { Phosphatase and tensin homologue } \\ \text { RING } & \text { Really interesting new gene } \\ \text { SCF } & \text { Skp1-Cullin 1-F-box } \\ \text { siRNA } & \text { small interfering RNA } \\ \text { SKP1 } & \text { S-phase kinase-associated protein 1 } \\ \text { SMURF1 } & \text { SMAD-specific E3 ubiquitin protein ligases } \\ \text { UPS } & \text { Ubiquitin proteasome system } \\ \text { VEGF-R2 } & \text { Vascular endothelial growth factor receptor-2 } \\ \text { WWP-1 } & \text { WW domain containing E3 ubiquitin protein ligase 1 }\end{array}$

\section{REFERENCES}

[1]. Frescas D, Pagano M. Deregulated proteolysis by the F-box proteins SKP2 and beta-TrCP: tipping the scales of cancer. Nat Rev Cancer. 2008; 8:438-449. [PubMed: 18500245]

[2]. Ahn Y, Hwang CY, Lee SR, Kwon KS, Lee C. The tumour suppressor PTEN mediates a negative regulation of the E3 ubiquitin-protein ligase Nedd4. Biochem J. 2008; 412:331-338. [PubMed: 18307411]

[3]. Hoeller D, Hecker CM, Dikic I. Ubiquitin and ubiquitin-like proteins in cancer pathogenesis. Nat Rev Cancer. 2006; 6:776-788. [PubMed: 16990855]

[4]. Hoeller D, Dikic I. Targeting the ubiquitin system in cancer therapy. Nature. 2009; 458:438-444. [PubMed: 19325623]

[5]. Rotin D, Kumar S. Physiological functions of the HECT family of ubiquitin ligases. Nat Rev Mol Cell Biol. 2009; 10:398-409. [PubMed: 19436320]

[6]. Eisenhaber B, Chumak N, Eisenhaber F, Hauser MT. The ring between ring fingers (RBR) protein family. Genome Biol. 2007; 8:209. [PubMed: 17367545]

[7]. Zhang J, Wan L, Dai X, Sun Y, Wei W. Functional characterization of Anaphase Promoting Complex/Cyclosome (APC/C) E3 ubiquitin ligases in tumorigenesis. Biochim Biophys Acta. 2014; 1845:277-293. [PubMed: 24569229]

[8]. Nakayama KI, Nakayama K. Ubiquitin ligases: cell-cycle control and cancer. Nat Rev Cancer. 2006; 6:369-381. [PubMed: 16633365]

[9]. Bernassola F, Karin M, Ciechanover A, Melino G. The HECT family of E3 ubiquitin ligases: multiple players in cancer development. Cancer Cell. 2008; 14:10-21. [PubMed: 18598940]

[10]. Scheffner M, Kumar S. Mammalian HECT ubiquitin-protein ligases: biological and pathophysiological aspects. Biochim Biophys Acta. 2014; 1843:61-74. [PubMed: 23545411]

[11]. Yang B, Kumar S. Nedd4 and Nedd4-2: closely related ubiquitin-protein ligases with distinct physiological functions. Cell Death Differ. 2010; 17:68-77. [PubMed: 19557014]

[12]. Donovan P, Poronnik P. Nedd4 and Nedd4-2: ubiquitin ligases at work in the neuron. Int J Biochem Cell Biol. 2013; 45:706-710. [PubMed: 23262292]

[13]. Chen C, Matesic LE. The Nedd4-like family of E3 ubiquitin ligases and cancer. Cancer Metastasis Rev. 2007; 26:587-604. [PubMed: 17726579]

[14]. Shearwin-Whyatt L, Dalton HE, Foot N, Kumar S. Regulation of functional diversity within the Nedd4 family by accessory and adaptor proteins. Bioessays. 2006; 28:617-628. [PubMed: 16700065] 
[15]. Staub O, Dho S, Henry P, Correa J, Ishikawa T, McGlade J, Rotin D. WW domains of Nedd4 bind to the proline-rich PY motifs in the epithelial Na+ channel deleted in Liddle's syndrome. Embo J. 1996; 15:2371-2380. [PubMed: 8665844]

[16]. Shenoy SK, Xiao K, Venkataramanan V, Snyder PM, Freedman NJ, Weissman AM. Nedd4 mediates agonist-dependent ubiquitination, lysosomal targeting, and degradation of the beta2adrenergic receptor. J Biol Chem. 2008; 283:22166-22176. [PubMed: 18544533]

[17]. Schwarz LA, Hall BJ, Patrick GN. Activity-dependent ubiquitination of GluA1 mediates a distinct AMPA receptor endocytosis and sorting pathway. J Neurosci. 2010; 30:16718-16729. [PubMed: 21148011]

[18]. Lin A, Hou Q, Jarzylo L, Amato S, Gilbert J, Shang F, Man HY. Nedd4-mediated AMPA receptor ubiquitination regulates receptor turnover and trafficking. J Neurochem. 2011; 119:2739. [PubMed: 21338354]

[19]. Sakata T, Sakaguchi H, Tsuda L, Higashitani A, Aigaki T, Matsuno K, Hayashi S. Drosophila Nedd4 regulates endocytosis of notch and suppresses its ligand-independent activation. Curr Biol. 2004; 14:2228-2236. [PubMed: 15620649]

[20]. Wilkin MB, Carbery AM, Fostier M, Aslam H, Mazaleyrat SL, Higgs J, Myat A, Evans DA, Cornell M, Baron M. Regulation of notch endosomal sorting and signaling by Drosophila Nedd4 family proteins. Curr Biol. 2004; 14:2237-2244. [PubMed: 15620650]

[21]. Fan CD, Lum MA, Xu C, Black JD, Wang X. Ubiquitin-dependent regulation of phospho-AKT dynamics by the ubiquitin E3 ligase, NEDD4-1, in the insulin-like growth factor-1 response. J Biol Chem. 2013; 288:1674-1684. [PubMed: 23195959]

[22]. Vecchione A, Marchese A, Henry P, Rotin D, Morrione A. The Grb10/Nedd4 complex regulates ligand-induced ubiquitination and stability of the insulin-like growth factor I receptor. Mol Cell Biol. 2003; 23:3363-3372. [PubMed: 12697834]

[23]. Murdaca J, Treins C, Monthouel-Kartmann MN, Pontier-Bres R, Kumar S, Van Obberghen E, Giorgetti-Peraldi S. Grb10 prevents Nedd4-mediated vascular endothelial growth factor receptor-2 degradation. J Biol Chem. 2004; 279:26754-26761. [PubMed: 15060076]

[24]. Magnifico A, Ettenberg S, Yang C, Mariano J, Tiwari S, Fang S, Lipkowitz S, Weissman AM. WW domain HECT E3s target Cbl RING finger E3s for proteasomal degradation. J Biol Chem. 2003; 278:43169-43177. [PubMed: 12907674]

[25]. Woelk T, Oldrini B, Maspero E, Confalonieri S, Cavallaro E, Di Fiore PP, Polo S. Molecular mechanisms of coupled monoubiquitination. Nat Cell Biol. 2006; 8:1246-1254. [PubMed: 17013377]

[26]. Al Sorkhy M, Craig R, Market B, Ard R, Porter LA. The cyclin-dependent kinase activator, Spy1A, is targeted for degradation by the ubiquitin ligase NEDD4. J Biol Chem. 2009; 284:2617-2627. [PubMed: 19054764]

[27]. Salah Z, Cohen S, Itzhaki E, Aqeilan RI. NEDD4 E3 ligase inhibits the activity of the Hippo pathway by targeting LATS1 for degradation. Cell Cycle. 2013; 12

[28]. Wang X, Trotman LC, Koppie T, Alimonti A, Chen Z, Gao Z, Wang J, Erdjument-Bromage H, Tempst P, Cordon-Cardo C, Pandolfi PP, Jiang X. NEDD4-1 is a proto-oncogenic ubiquitin ligase for PTEN. Cell. 2007; 128:129-139. [PubMed: 17218260]

[29]. Xu C, Fan CD, Wang X. Regulation of Mdm2 protein stability and the p53 response by NEDD4-1 E3 ligase. Oncogene. 2014

[30]. Monami G, Emiliozzi V, Morrione A. Grb10/Nedd4-mediated multiubiquitination of the insulinlike growth factor receptor regulates receptor internalization. J Cell Physiol. 2008; 216:426-437. [PubMed: 18286479]

[31]. Platta HW, Abrahamsen H, Thoresen SB, Stenmark H. Nedd4-dependent lysine-11-linked polyubiquitination of the tumour suppressor Beclin 1. Biochem J. 2012; 441:399-406. [PubMed: 21936852]

[32]. Luo QF, Chen W, Zhang ST. Identification of Nedd4 as a novel regulator in Hedgehog signaling. Chin Med J (Engl). 2012; 125:3851-3855. [PubMed: 23106887]

[33]. Harvey KF, Harvey NL, Michael JM, Parasivam G, Waterhouse N, Alnemri ES, Watters D, Kumar S. Caspase-mediated cleavage of the ubiquitin-protein ligase Nedd4 during apoptosis. J Biol Chem. 1998; 273:13524-13530. [PubMed: 9593687] 
[34]. Dinudom A, Fotia AB, Lefkowitz RJ, Young JA, Kumar S, Cook DI. The kinase Grk2 regulates Nedd4/Nedd4-2-dependent control of epithelial Na+ channels. Proc Natl Acad Sci U S A. 2004; 101:11886-11890. [PubMed: 15284439]

[35]. Dai B, Pieper RO, Li D, Wei P, Liu M, Woo SY, Aldape KD, Sawaya R, Xie K, Huang S. FoxM1B regulates NEDD4-1 expression, leading to cellular transformation and full malignant phenotype in immortalized human astrocytes. Cancer Res. 2010; 70:2951-2961. [PubMed: 20332230]

[36]. Kwak YD, Wang B, Li JJ, Wang R, Deng Q, Diao S, Chen Y, Xu R, Masliah E, Xu H, Sung JJ, Liao FF. Upregulation of the E3 ligase NEDD4-1 by oxidative stress degrades IGF-1 receptor protein in neurodegeneration. J Neurosci. 2012; 32:10971-10981. [PubMed: 22875931]

[37]. Kovacevic Z, Chikhani S, Lui GY, Sivagurunathan S, Richardson DR. The iron-regulated metastasis suppressor NDRG1 targets NEDD4L, PTEN, and SMAD4 and inhibits the PI3K and Ras signaling pathways. Antioxid Redox Signal. 2013; 18:874-887. [PubMed: 22462691]

[38]. Liu JW, Liu L, Inuzuka P, Liu H, Wang J, Wei Z. Beta-TRCP-mediated degradation of NEDD4 inhibits tumorigenesis through modulating the PTEN/Akt signaling pathway. Oncotarget. 2014 W. In Press.

[39]. Hong SW, Moon JH, Kim JS, Shin JS, Jung KA, Lee WK, Jeong SY, Hwang JJ, Lee SJ, Suh YA, Kim I, Nam KY, Han S, Kim JE, Kim KP, Hong YS, Lee JL, Lee WJ, Choi EK, Lee JS, Jin $\mathrm{DH}, \mathrm{Kim}$ TW. p34 is a novel regulator of the oncogenic behavior of NEDD4-1 and PTEN. Cell Death Differ. 2014; 21:146-160. [PubMed: 24141722]

[40]. Jung S, Li C, Jeong D, Lee S, Ohk J, Park M, Han S, Duan J, Kim C, Yang Y, Kim KI, Lim JS, Kang YS, Lee MS. Oncogenic function of p34SEI-1 via NEDD41mediated PTEN ubiquitination/ degradation and activation of the PI3K/AKT pathway. Int J Oncol. 2013; 43:1587-1595. [PubMed: 23970032]

[41]. Lonne GK, Masoumi KC, Lennartsson J, Larsson C. Protein kinase Cdelta supports survival of MDA-MB-231 breast cancer cells by suppressing the ERK1/2 pathway. J Biol Chem. 2009; 284:33456-33465. [PubMed: 19833733]

[42]. Eide PW, Cekaite L, Danielsen SA, Eilertsen IA, Kjenseth A, Fykerud TA, Agesen TH, Bruun J, Rivedal E, Lothe RA, Leithe E. NEDD4 is overexpressed in colorectal cancer and promotes colonic cell growth independently of the PI3K/PTEN/AKT pathway. Cell Signal. 2013; 25:1218. [PubMed: 22974840]

[43]. Amodio N, Scrima M, Palaia L, Salman AN, Quintiero A, Franco R, Botti G, Pirozzi P, Rocco G, De Rosa N, Viglietto G. Oncogenic role of the E3 ubiquitin ligase NEDD4-1, a PTEN negative regulator, in non-small-cell lung carcinomas. Am J Pathol. 2010; 177:2622-2634. [PubMed: 20889565]

[44]. Liu Y, Oppenheim RW, Sugiura Y, Lin W. Abnormal development of the neuromuscular junction in Nedd4-deficient mice. Dev Biol. 2009; 330:153-166. [PubMed: 19345204]

[45]. Kawabe H, Neeb A, Dimova K, Young S. M., Jr. Takeda M, Katsurabayashi S, Mitkovski M, Malakhova OA, Zhang DE, Umikawa M, Kariya K, Goebbels S, Nave KA, Rosenmund C, Jahn O, Rhee J, Brose N. Regulation of Rap2A by the ubiquitin ligase Nedd4-1 controls neurite development. Neuron. 2010; 65:358-372. [PubMed: 20159449]

[46]. Fouladkou F, Lu C, Jiang C, Zhou L, She Y, Walls JR, Kawabe H, Brose N, Henkelman RM, Huang A, Bruneau BG, Rotin D. The ubiquitin ligase Nedd4-1 is required for heart development and is a suppressor of thrombospondin-1. J Biol Chem. 2010; 285:6770-6780. [PubMed: 20026598]

[47]. Cao XR, Lill NL, Boase N, Shi PP, Croucher DR, Shan H, Qu J, Sweezer EM, Place T, Kirby PA, Daly RJ, Kumar S, Yang B. Nedd4 controls animal growth by regulating IGF-1 signaling. Sci Signal. 2008; 1:ra5. [PubMed: 18812566]

[48]. Rotin D, Kumar S. Physiological functions of the HECT family of ubiquitin ligases. Nat Rev Mol Cell Biol. 2009; 10:398-409. [PubMed: 19436320]

[49]. Camera D, Boase NA, Kumar S, Pow DV, Poronnik P. Subtle gait abnormalities in Nedd4 heterozygous mice. Behav Brain Res. 2014; 260:15-24. [PubMed: 24280120] 
[50]. Nagpal P, Plant PJ, Correa J, Bain A, Takeda M, Kawabe H, Rotin D, Bain JR, Batt JA. The ubiquitin ligase Nedd4-1 participates in denervation-induced skeletal muscle atrophy in mice. PLoS One. 2012; 7:e46427. [PubMed: 23110050]

[51]. Tanksley JP, Chen X, Coffey RJ. NEDD4L is downregulated in colorectal cancer and inhibits canonical WNT signaling. PLoS One. 2013; 8:e81514. [PubMed: 24312311]

[52]. Wang YY, Ye ZY, Zhao ZS, Tao HQ, Li SG. Systems biology approach to identification of biomarkers for metastatic progression in gastric cancer. J Cancer Res Clin Oncol. 2010; 136:135-141. [PubMed: 19649653]

[53]. Yang Z, Yuan XG, Chen J, Lu NH. Is NEDD4-1 a negative regulator of phosphatase and tensin homolog in gastric carcinogenesis? World J Gastroenterol. 2012; 18:6345-6348. [PubMed: 23180960]

[54]. Kapoor N, Bartoszewski R, Qadri YJ, Bebok Z, Bubien JK, Fuller CM, Benos DJ. Knockdown of ASIC1 and epithelial sodium channel subunits inhibits glioblastoma whole cell current and cell migration. J Biol Chem. 2009; 284:24526-24541. [PubMed: 19561078]

[55]. Herner A, Sauliunaite D, Michalski CW, Erkan M, De Oliveira T, Abiatari I, Kong B, Esposito I, Friess H, Kleeff J. Glutamate increases pancreatic cancer cell invasion and migration via AMPA receptor activation and Kras-MAPK signaling. Int J Cancer. 2011; 129:2349-2359. [PubMed: 21207374]

[56]. Du P, Hu S, Cheng Y, Li F, Li M, Li J, Yi L, Feng H. Photodynamic therapy leads to death of C6 glioma cells partly through AMPAR. Brain Res. 2012; 1433:153-159. [PubMed: 22177774]

[57]. Wirawan E, Lippens S, Vanden Berghe T, Romagnoli A, Fimia GM, Piacentini M, Vandenabeele P. Beclin1: a role in membrane dynamics and beyond. Autophagy. 2012; 8:6-17. [PubMed: 22170155]

[58]. Fu LL, Cheng Y, Liu B. Beclin-1: autophagic regulator and therapeutic target in cancer. Int J Biochem Cell Biol. 2013; 45:921-924. [PubMed: 23420005]

[59]. Paolino M, Choidas A, Wallner S, Pranjic B, Uribesalgo I, Loeser S, Jamieson AM, Langdon WY, Ikeda F, Fededa JP, Cronin SJ, Nitsch R, Schultz-Fademrecht C, Eickhoff J, Menninger S, Unger A, Torka R, Gruber T, Hinterleitner R, Baier G, Wolf D, Ullrich A, Klebl BM, Penninger JM. The E3 ligase Cbl-b and TAM receptors regulate cancer metastasis via natural killer cells. Nature. 2014; 507:508-512. [PubMed: 24553136]

[60]. Huber RM, Rajski M, Sivasankaran B, Moncayo G, Hemmings BA, Merlo A. Deltex-1 activates mitotic signaling and proliferation and increases the clonogenic and invasive potential of U373 and LN18 glioblastoma cells and correlates with patient survival. PLoS One. 2013; 8:e57793. [PubMed: 23451269]

[61]. Chen HX, Sharon E. IGF-1R as an anti-cancer target--trials and tribulations. Chin J Cancer. 2013; 32:242-252. [PubMed: 23601239]

[62]. Corvaia N, Beck A, Caussanel V, Goetsch L. Insulin-like growth factor receptor type I as a target for cancer therapy. Front Biosci (Schol Ed). 2013; 5:439-450. [PubMed: 23277061]

[63]. Visser S, Yang X. LATS tumor suppressor: a new governor of cellular homeostasis. Cell Cycle. 2010; 9:3892-3903. [PubMed: 20935475]

[64]. Liu AM, Wong KF, Jiang X, Qiao Y, Luk JM. Regulators of mammalian Hippo pathway in cancer. Biochim Biophys Acta. 2012; 1826:357-364. [PubMed: 22683405]

[65]. Nag S, Zhang X, Srivenugopal KS, Wang MH, Wang W, Zhang R. Targeting MDM2-p53 interaction for cancer therapy: are we there yet? Curr Med Chem. 2014; 21:553-574. [PubMed: 24180275]

[66]. Zhao Y, Yu H, Hu W. The regulation of MDM2 oncogene and its impact on human cancers. Acta Biochim Biophys Sin (Shanghai). 2014; 46:180-189. [PubMed: 24389645]

[67]. Kumar A, Rajendran V, Sethumadhavan R, Purohit R. AKT kinase pathway: a leading target in cancer research. The Scientific World Journal. 2013; 2013:756134.

[68]. Hopkins BD, Hodakoski C, Barrows D, Mense SM, Parsons RE. PTEN function: the long and the short of it. Trends Biochem Sci. 2014; 39:183-190. [PubMed: 24656806]

[69]. Golipour A, Myers D, Seagroves T, Murphy D, Evan GI, Donoghue DJ, Moorehead RA, Porter LA. The Spy1/RINGO family represents a novel mechanism regulating mammary growth and tumorigenesis. Cancer Res. 2008; 68:3591-3600. [PubMed: 18483240] 
[70]. Clarke JM, Hurwitz HI. Targeted inhibition of VEGF receptor 2: an update on ramucirumab. Expert Opin Biol Ther. 2013; 13:1187-1196. [PubMed: 23803182] 


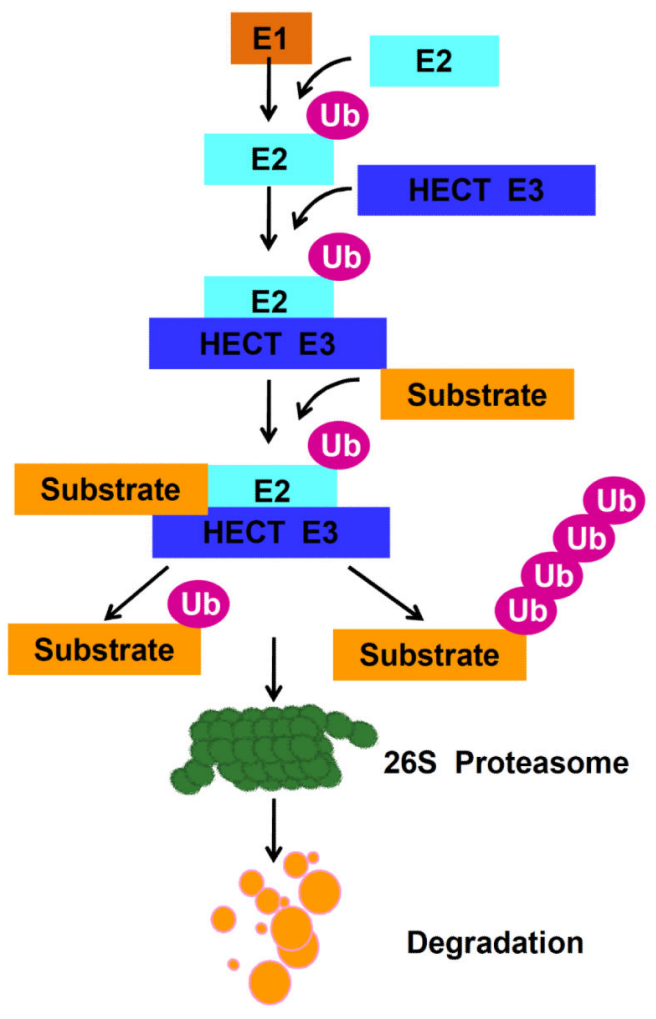

Fig. (1).

A schematic illustration of ubiquitylation mechanism. Ubiquitination is catalyzed by the E1 ubiquitin-activating enzyme, the E2 ubiquitin-conjugating enzyme, and the E3 ubiquitinprotein ligase. The E1 activates ubiquitin in an ATP-dependent manner, and subsequently transfers ubiquitin to the E2 enzyme. Then, E2 binds with E3 ligases and E3 ligases subsequently transfer the ubiquitin to substrates for degradation by the $26 \mathrm{~S}$ proteasome. 


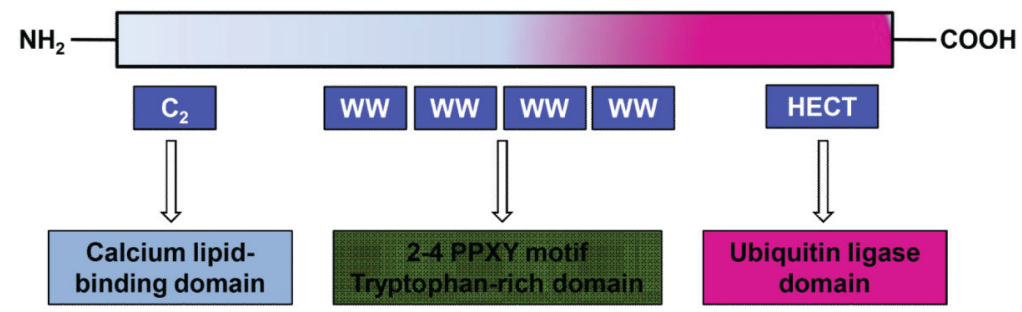

Fig. (2).

A schematic diagram of the structure of NEDD4 protein. The C2 domain translocates the protein to the membrane. The HECT domain is responsible for ubiquitin-protein ligation. The central two to four double tryptophan residue (WW) domains are responsible for protein-protein interaction through recognizing the proline-containing motifs (PY motifs; PPXY) present in most of its substrates. 


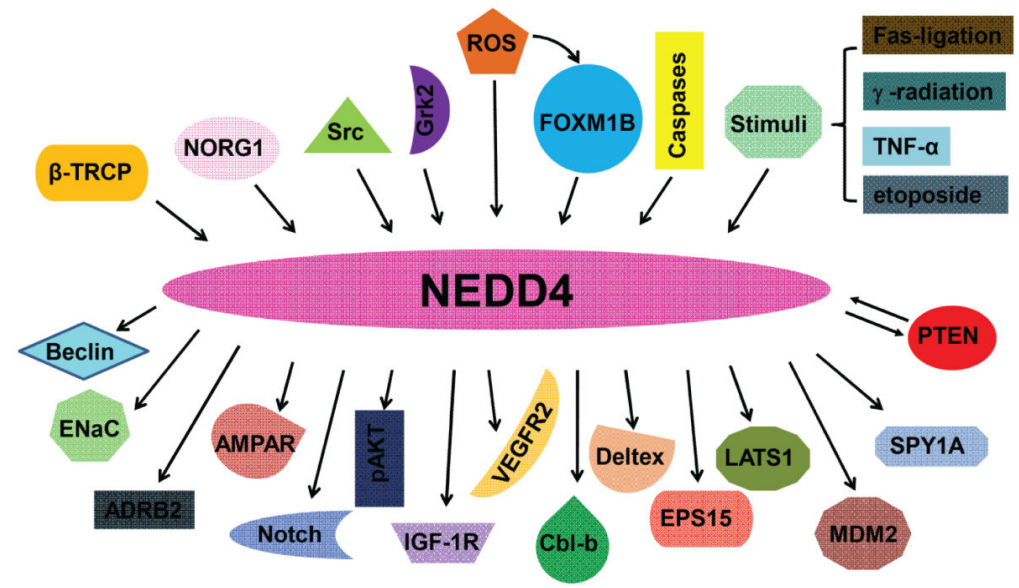

Fig. (3).

Illustrated pathways for NEDD4-mediated degradation of its substrates as well as the identified NEDD4 upstream regulators. 


\section{Table 1}

Summary of known ubiquitin substrates of NEDD4.

\begin{tabular}{|c|c|c|}
\hline Substrates & Functions & Reference \\
\hline $\mathrm{ENaC}$ & Sodium homeostasis; high expression in ghoblastoma cells & {$[15,54]$} \\
\hline ADRB2 & A member of the G protein-coupled receptor superfamily; dyregulation in multiple human cancers & {$[16]$} \\
\hline AMPAR & $\begin{array}{c}\text { Excitatory synaptic transmission; promotion of cell migration and invasion in pancreatic cancer; regulation of } \\
\text { apoptosis in glioma cells. }\end{array}$ & {$[17,18,55,56]$} \\
\hline Beclin 1 & Regulation of autophagy, development and tumorigenesis; deletion in breast, prostate and other tumors. & {$[31,57,58]$} \\
\hline Cbl-b & An E3 ligase; regulation of cancer metastasis & {$[24,59]$} \\
\hline Deltex & $\begin{array}{c}\text { Regulator of Notch signaling pathway; regulation of MAPK/ERK and PI3K/PKB pathways; promotion of cell } \\
\text { growth and invasion in glioblastoma }\end{array}$ & {$[19,60]$} \\
\hline EPS15 & Involved in cell growth regulation; a protein in EGFR pathway; & {$[25]$} \\
\hline IGF-1R & Receptor tyrosine kinase, which mediates actions of IGF-1; overexpressed in most malignant tissues. & {$[22,61,62]$} \\
\hline LATS1 & A negative regulator of YAP1 in the Hippo signaling pathway; control of organ size and cell proliferation. & {$[27,63,64]$} \\
\hline MDM2 & $\begin{array}{c}\text { E3 ubiquitin ligase; mediates ubiquitination and degradation of p53/TP53; overexpression in most } \\
\text { malignancies. }\end{array}$ & {$[29,65,66]$} \\
\hline Notch & $\begin{array}{c}\text { Regulation of cell differentiation, proliferation, apoptosis, invasion and angiogenesis; overexpression in most } \\
\text { human cancers. }\end{array}$ & {$[19,20]$} \\
\hline pAKT & $\begin{array}{c}\text { Regulates many processes including metabolism, proliferation, migration, and angiogenesis; overexpression in } \\
\text { most malignancies. }\end{array}$ & {$[21,67]$} \\
\hline pTEN & Tumor suppressor; negatively regulating AKT pathway; mutation in most human cancers. & {$[28,68]$} \\
\hline Spy1A & Cell cycle activator; Override the DNA damage response; regulating mammary growth and tumorigenesis. & {$[26,69]$} \\
\hline VEGF-R2 & $\begin{array}{l}\text { Regulation of angiogenesis, vascular development, and vascular permeability; Promotes proliferation, survival, } \\
\text { migration and differentiation of endothelial cells. Overexpression in most human cancers. }\end{array}$ & {$[23,70]$} \\
\hline
\end{tabular}

Curr Cancer Drug Targets. Author manuscript; available in PMC 2015 January 22. 